\title{
Effects of Dietary Saccharomyces cerevisiae YFI-SC2 on the Growth Performance, Intestinal Morphology, Immune Parameters, Intestinal Microbiota, and Disease Resistance of Crayfish (Procambarus clarkia)
}

\author{
Yan Xu ${ }^{1}$, Yiqun Li $^{1}$, Mingyang Xue ${ }^{1}$, Tao Yang ${ }^{2}$, Xiaowen Luo ${ }^{1}$, Yuding Fan ${ }^{1}$, , Yan Meng ${ }^{1}$, Wenzhi Liu ${ }^{1}$, \\ Ge Lin ${ }^{1}$, Bo Li ${ }^{3}$, Lingbing Zeng ${ }^{1, *}$ and Yong Zhou ${ }^{1, *}$ \\ 1 Yangtze River Fisheries Research Institute, Chinese Academy of Fishery Sciences, Wuhan 430223, China; \\ xy13033732426@163.com (Y.X.); liyq@yfi.ac.cn (Y.L.); xmy@yfi.ac.cn (M.X.); m18790069727@163.com (X.L.); \\ fanyd@yfi.ac.cn (Y.F.); mengy@yfi.ac.cn (Y.M.); liuwenzhialisa@yfi.ac.cn (W.L.); linge0310@163.com (G.L.) \\ 2 Animal Health Research Institute, Tongwei Co., Ltd., Chengdu 610041, China; yangt@tongwei.com \\ 3 Wuhan Academy of Agricultural Science, Wuhan 430207, China; libowuhan003@163.com \\ * Correspondence: zlb@yfi.ac.cn (L.Z.); zhouy@yfi.ac.cn (Y.Z.); Tel.: +86-18627783535 (L.Z.); \\ +86-13554642560 (Y.Z.)
}

check for updates

Citation: Xu, Y.; Li, Y.; Xue, M.; Yang, T.; Luo, X.; Fan, Y.; Meng, Y.; Liu, W.; Lin, G.; Li, B.; et al. Effects of Dietary Saccharomyces cerevisiae YFI-SC2 on the Growth Performance, Intestinal Morphology, Immune Parameters, Intestinal Microbiota, and Disease Resistance of Crayfish (Procambarus clarkia). Animals 2021, 11, 1963. https://doi.org/10.3390/ani11071963

Academic Editors:

Roberta Imperatore and

Marina Paolucci

Received: 25 May 2021

Accepted: 27 June 2021

Published: 30 June 2021

Publisher's Note: MDPI stays neutral with regard to jurisdictional claims in published maps and institutional affiliations.

Copyright: () 2021 by the authors. Licensee MDPI, Basel, Switzerland. This article is an open access article distributed under the terms and conditions of the Creative Commons Attribution (CC BY) license (https:// creativecommons.org/licenses/by/ $4.0 /)$.
Simple Summary: Diseases of crayfish (Procambarus clarkia) are closely related to intestinal health. Therefore, it is important for crayfish aquaculture to keep intestinal health in an optimum condition. As a beneficial fungus, Saccharomyces cerevisiae can effectively compete to inhibit the reproduction of pathogenic bacteria, regulate the intestinal microecosystem, and promote animal growth and disease resistance. This study aimed to assess the effects of S. cerevisiae YFI-SC2 on the growth, immunity, and intestinal health of crayfish. The results demonstrated that the addition of S. cerevisiae to the feed could improve the growth performance, the immune response, the intestinal morphology, the structure of intestinal microbiota, and the resistance to pathogens of crayfish. Therefore, S. cerevisiae can be used as a potential probiotic in crayfish farming.

Abstract: The present study aimed to evaluate the effect of the dietary supplementation of Saccharomyces cerevisiae YFI-SC2 on the growth performance, intestinal morphology, immune parameters, intestinal microbiota, and disease resistance of crayfish (Procambarus clarkia). Crayfish were randomly assigned to six different boxes and two different groups in triplicate. The control group received a basal diet and the treatment group received a diet containing $S$. cerevisiae at $10^{7} \mathrm{CFU} / \mathrm{g}$. After feeding for 28 days, crayfish of the treatment group exhibited a significantly better weight gain ratio (WGR) and a specific growth rate (SGR) $(p<0.05)$ than crayfish of the control group. Compared to the treatment group, the control group intestines showed an oedema connective tissue layer and a weak muscle layer. For immune-related genes, Crustin2 expression was similar between the groups, whereas Lysozyme and prophenoloxidase from treatment group expression levels were upregulated significantly $(p<0.05)$ after 14 and 28 days of feeding. Prophenoloxidase showed the highest expression, with 10.5- and 8.2-fold higher expression than in the control group at 14 and 28 days, respectively. The intestinal microbiota community structure was markedly different between the two groups. After 14 and 28 days of feeding, the relative abundance of Cetobacterium and Lactobacillus increased, whereas Citrobacter and Bacteroides decreased in the treatment group compared with that of the control group. The challenge test showed that crayfish of the treatment group had a significantly enhanced resistance against Citrobacter freundii $(p<0.05)$. Our results suggest that a S. cerevisiae-containing diet positively influenced the health status, immune parameters, intestinal microbiota composition, and disease resistance of crayfish.

Keywords: crayfish; growth; immune; intestinal microbiota; intestinal morphology; Saccharomyces cerevisiae 


\section{Introduction}

Crayfish belong to the subphylum Crustacea, the order Decapoda, and the family Cambaridae [1]. Crayfish is native to eastern North America. It was first introduced to Japan in 1918, and then entered China in the 1930s [2]. Its bright color and delicious taste mean that crayfish are loved by consumers, and they have recently become a commercially important freshwater species in China [3]. In 2018, world production of crayfish was 1.71 million tons [4], and it was 1.64 million tons in China [5]. Comparing with that in 2018, China's total production of crayfish reached 2.09 million tons, with an increase of $27.52 \%$ in 2019 [5]. However, with the development of the industry, the reports on the occurrence of crayfish diseases were also gradually increased. C. freundii, as a typical conditional pathogen, has strong pathogenicity and lethality toward crayfish. This may result in economic losses to the crayfish aquaculture industry [6]. Many crayfish diseases are closely related to intestinal health, especially the structure of the intestinal microbiota [7]. The intestinal microbiota's structural composition, diversity, and stability are important factors affecting host health [8]. Meanwhile, as invertebrates, the innate immune system of crayfish plays an important role in resistance to disease [9]. Toll-like receptors and prophenoloxidase are important parts of the innate immune signal recognition and transduction system [10]. Crustin2 and lysozyme are classes of antibacterial peptides with broad-spectrum antibacterial activity that have important antibacterial and antiviral effects $[11,12]$. Therefore, maintaining the dynamic balance of the intestinal microbiota and promoting immune gene expression are important for the healthy development of the crayfish industry.

Probiotics have been proven to be beneficial in improving aquatic animal health and immunity via modulation of the intestinal microbiota [13]. They can also improve feed digestibility and the absorption rate, promote healthy intestinal morphology, and enhance disease resistance [14]. S. cerevisiae is a beneficial fungus that can effectively compete with and inhibit the reproduction of pathogenic bacteria in the process of proliferation. In addition, S. cerevisiae can produce cell wall polysaccharides, active bacteria, minerals, vitamins, and growth-promoting factors during the fermentation process, which favor the improvement of nutrient digestion, promote the development of the intestinal mucosa, and maintain the balance of the intestinal microbiota in animals [15-17]. Studies have shown that $S$. cerevisiae can promote the growth, immunity, and disease resistance, and can improve the intestinal microbiota structure, of gibel carp (Carassius auratus gibelio), common carp (Cyprinus carpio), and Arapaima gigas [17-19]. Thus, S. cerevisiae provides an important reference for the development of probiotics in aquatic products. A number of studies verified the beneficial effects of S. cerevisiae on white shrimp (Litopenaeus vannamei) [20,21]; however, data regarding the effects of probiotic bacteria or S. cerevisiae on the growth, immunity, and intestinal health of crayfish are limited.

In the present study, we aimed to add S. cerevisiae YFI-SC2 to crayfish feed and study the effect of S. cerevisiae YFI-SC2 on growth performance, intestinal morphology, the immune response, and the intestinal microbial community composition, to provide a useful reference for the development of the crayfish industry.

\section{Materials and Methods}

\subsection{Experimental Animals}

The experimental crayfish $(13.71 \pm 0.58 \mathrm{~g})$ were obtained from a local farm in Qianjiang, Hubei, China. Crayfish were temporary cultured in breeding boxes $(75 \mathrm{~cm} \times 50 \mathrm{~cm} \times 25 \mathrm{~cm})$ for 7 days before the feeding experiments. Each breeding box was filled with $25 \mathrm{~L}$ of fresh water $\left(\mathrm{pH} 7.8 \pm 0.2\right.$, temperature $23 \pm 1{ }^{\circ} \mathrm{C}$, dissolved oxygen $\left.6.5 \pm 0.5 \mathrm{mg} / \mathrm{L}\right)$ and contained two evasion devices $(25 \mathrm{~cm} \times 20 \mathrm{~cm} \times 12 \mathrm{~cm}$, unsealed at one end). Approximately $50 \%$ of the water was exchanged from each box on a daily basis along with the siphoning of fecal matter from the bottom. The experimental water was tap water that was aerated for more than $48 \mathrm{~h}$. The crayfish were fed commercial pellets supplied by Tongwei Co., Ltd., Chengdu, China ( $\geq 28 \%$ protein, $\geq 3 \%$ fat, $\leq 12 \%$ water, and $\leq 18 \%$ ash) twice daily (9:00 and 17:00). The crayfish were fed with $1.5 \%$ of their total body weight. All experimental 
procedures were conducted according to guidelines of the appropriate Animal Experimental Ethical Inspection of Laboratory Animal Centre, Yangtze River Fisheries Research Institute, Chinese Academy of Fishery Sciences (ID Number: YFI2021-zhouyong-01).

\subsection{Yeast Strains and Growth Conditions}

S. cerevisiae YFI-SC2 was isolated from the intestinal tract of crayfish and stored at the China Center for Type Culture Collection (CCTCC), Wuhan University, whose preservation number was CCTCC M2021311. S. cerevisiae was cultured overnight in yeast peptone dextrose adenine (YPDA; Qingdao biological technology Co., Ltd., Qingdao, China) at $30{ }^{\circ} \mathrm{C}$ and resuspended in sterilized phosphate-buffered saline (PBS). The colony forming units $(\mathrm{CFU})$ per milliliter of $S$. cerevisiae culture was determined by the plate dilution counting method. The $S$. cerevisiae resuspended cells were added to the commercial basal feed at $10^{7} \mathrm{CFU} / \mathrm{g}$ of feed [21]. The feed was vacuum-dried at $30^{\circ} \mathrm{C}$ overnight and stored at $4{ }^{\circ} \mathrm{C}$. The feed was prepared in this way every 3 days.

\subsection{Feeding Frequency}

After 7 days of acclimation, the experimental crayfish were divided into 6 boxes each containing 80 crayfish. The boxes were randomly divided into the treatment group (TG) and the control group (CG) (three boxes each). The treatment group was fed S. cerevisiae feed, and the control group was fed the basal commercial feed for 28 days. In order to clearly explore the probiotic effect of $S$. cerevisiae on crayfish, sampling analysis was conducted on the 14th and 28th days of culturation.

\subsection{Growth for Performance and Sample Collection}

\subsubsection{Growth Performance}

Weights were measured at the beginning and at the 14th and 28th days of the experiment. The growth parameter indices, the weight gain ratio (WGR), and the specific growth rate (SGR) were used to measure the growth performance of the crayfish. These indicators, and the survival rate, were calculated according to the formulae:

$$
\begin{gathered}
\text { WGR }(\%)=100 \times(\mathrm{Wf}-\mathrm{Wi}) / \mathrm{Wi} \\
\text { SGR }(\% / \text { day })=100 \times(\ln \mathrm{Wf}-\ln \mathrm{Wi}) / \mathrm{T} \\
\text { Survival rate }(\%)=100 \times \mathrm{Ni} / \mathrm{Nf}
\end{gathered}
$$

where, the Wf is the weight of the crayfish at sampling; Wi is the initial weight of the crayfish; $\mathrm{T}$ is the feeding day when the sample was collected; $\mathrm{Ni}$ is the initial number of the crayfish; and $\mathrm{Nf}$ is the number of the crayfish at sampling.

\subsubsection{Sample Collection}

On the 14th and 28th day of the experiment, 8 crayfish were randomly collected per box and aseptically sacrificed in an ice-bath. The anterior intestines were fixed in neutral $4 \%$ paraformaldehyde to make tissue sections. The whole intestinal tissue was frozen rapidly in liquid nitrogen and stored at $-80^{\circ} \mathrm{C}$ for Illumina sequencing (Illumina, San Diego, CA, USA). Hepatopancreases were placed in an RNase-free centrifuge tube with $200 \mu \mathrm{L}$ TRIzol and stored at $-80^{\circ} \mathrm{C}$ for quantitative real-time reverse transcription PCR (qRT-PCR).

\subsection{Histopathology Analysis}

The anterior intestine tissues were fixed in $4 \%$ paraformaldehyde for $24 \mathrm{~h}$, dehydrated in a sequential series of alcohol (50-95\%), and embedded in paraffin. Tissue sections (5 $\mu \mathrm{m}$ thick) were stained with hematoxylin and eosin (H\&E). The intestinal structure was analyzed and photographed under a microscope (Olympus BX53 microscope, Tokyo, Japan). 


\subsection{Real-Time PCR Analysis of Immune-Related Genes}

Total RNA was isolated using the TRIzol reagent (Invitrogen, Carlsbad, CA, USA) and the residual trace DNA was removed using DNase I (Takara, Dalian, China). Complementary DNA (cDNA) was synthesized using a SuperMix kit (TransGen Biotech, Beijing, China). The cDNA was used as the template for the quantitative real-time PCR (qPCR) step, the reaction mixture for which was comprised of $2 \mu \mathrm{L}$ of diluted cDNA sample, $10 \mu \mathrm{L}$ of Power $2 \times$ TB Green Fast PCR Mix (Takara), $0.8 \mu \mathrm{L}$ of each primer (Table 1) (10 mol/L), and $6.4 \mu \mathrm{L}$ of $\mathrm{H}_{2} \mathrm{O}$. The qPCR cycle profile included 1 cycle at $95^{\circ} \mathrm{C}$ for $5 \mathrm{~min}$, followed by 40 cycles of $95{ }^{\circ} \mathrm{C}$ for $20 \mathrm{~s}, 55^{\circ} \mathrm{C}$ for $20 \mathrm{~s}$, and $72{ }^{\circ} \mathrm{C}$ for $20 \mathrm{~s}$. The primers for qPCR are shown in Table 1. Relative gene expression was assessed using the $2^{-\Delta \Delta \mathrm{Ct}}$ method [22]. The $18 \mathrm{~S}$ gene sequence was found on NCBI (MT829236.1), and the primer was designed by primer 5 , which was used as the internal control gene for cDNA normalization. All the experiments were repeated three times.

Table 1. List of primers used in this study.

\begin{tabular}{clc}
\hline Genes & \multicolumn{1}{c}{ Primer Sequence $\mathbf{( 5}^{\prime} \mathbf{- 3}^{\prime} \mathbf{)}$} & GenBank Number \\
\hline 18S-F & \multicolumn{1}{c}{ For } & \\
18S-R & TGGTGCATGGCCGTTCTTA & MT829236.1 \\
Crustin2-F & AATTGCTGGAGATCCGTCGAC & \\
Crustin2-R & GGGAAGAAAAGCACAATGGT & GQ301202.1 [23] \\
Prophenoloxidase-F & GGTATGGAGGTCGAGACAGG & \\
Prophenoloxidase-R & AGGTGGATCAGCCAGCAGT & EF595973.1 [24] \\
Lysozyme-F & GATAGTCAGCAGCGGAGGT & \\
Lysozyme-R & GGGTTTGCCAGCTTCATTCCAGT & GQ301200.1 [23] \\
Toll-like receptor-F & GACTTGTCCAAAAACGATATACG & KP259728.1 [25] \\
Toll-like receptor-R & TGCGTTACAGTAGTGAGCGAAT & \\
\hline & For V3-V4 regions of 16S rRNA gene & \\
\hline 338F & ACTCCTACGGGAGGCAGCA & \\
806R & GGACTACHVGGGTWTCTAAT & \\
\hline
\end{tabular}

\subsection{Genomic DNA Extraction and $16 \mathrm{~S}$ rRNA Gene Sequencing}

Bacterial genomic DNA was extracted using a Bacterial DNA Kit (Omega Biotek, Winooski, VT, USA) following the manufacturer's instructions. PCR amplification of the bacterial V3-V4 region of the $16 \mathrm{~S}$ rRNA gene was performed in a $50 \mu \mathrm{L}$ reaction. The reaction contained $25 \mu \mathrm{L}$ of Hot Start Taq $2 \times$ Master Mix (New England BioLabs Inc., Ipswich, MA, USA), $2 \mu \mathrm{L}$ of template DNA, $2 \mu \mathrm{L}$ of each primer (338F and 806R [26], Table 1), and deionized water. The reaction conditions comprised an initial denaturation at $95{ }^{\circ} \mathrm{C}$ for $30 \mathrm{~s}, 30$ cycles of $95{ }^{\circ} \mathrm{C}$ for $10 \mathrm{~s}, 55^{\circ} \mathrm{C}$ for $30 \mathrm{~s}$, and $72{ }^{\circ} \mathrm{C}$ for $30 \mathrm{~s}$, and a final extension step at $72{ }^{\circ} \mathrm{C}$ for $5 \mathrm{~min}$. After quality checking using agarose gel electrophoresis, the samples were sequenced on the Illumina MiSeq PE300 high-throughput sequencing platform. All sequencing reads were quality-filtered and assembled using the Mothur software package [27]. The final effective data were obtained using the UCHIME v4.2 software. Reads were clustered into operational taxonomical units (OTUs) at 97\% identity [28]. The abundances of the corresponding OTUs in each group were calculated at the phylum and genus levels. Chao 1 (bacterial richness index) and Shannon (bacterial diversity index) alpha diversity indexes were analyzed using Mothur (version v.1.30) [29]. Principle coordinate analysis ( $\mathrm{PCoA}$ ) was used to assess the species differences between samples. 


\subsection{Challenge Test}

The pathogenic $C$. freundii, isolated from crayfish intestines and preserved in our laboratory, was used in the challenge test. C. freundii was cultured $24 \mathrm{~h}$ in brain heart infusion plates (BHI, Qingdao biological technology co., Ltd. Qingdao, China) at $37^{\circ} \mathrm{C}$ and resuspended in sterilized phosphate-buffered saline (PBS). After 14 days of the feeding trial, 30 crayfish from each breeding box were immersed in a solution containing $C$. freundii $\left(2.5 \times 10^{7} \mathrm{CFU} / \mathrm{mL}\right)$ for $2 \mathrm{~h}$ and then transferred to the breeding box. Crayfish mortality was recorded every $24 \mathrm{~h}$ for 10 days. After 28 days of the feeding trial, the challenge was carried out again using the same method. The presence of $C$. freundii as the only etiological agent was confirmed by swabbing the intestinal tissues onto BHI plates and subsequent bacteria identification.

\subsection{Statistical and Correlation Analyses}

Statistical analysis was performed using SPSS (version 17.0; IBM Corp., Armonk, NY, USA). One-way analysis of variance (ANOVA) was used to analyze the differences between different treatments, and the LSD test was used to compare means. All data are presented as the mean $\pm \mathrm{SD}$. Differences were considered statistically significant at $p<0.05$.

\section{Results}

\subsection{Growth Performance}

After 14 days and 28 days of feeding, the survival rates of the two groups of crayfish were above $90 \%$ (Table 2), and there was no significant difference between the groups. Compared with that in the control group, growth tended to be improved in the treatment group after 14 days of feeding. However, there was no significant difference observed in the WGR and SGR $(p>0.05)$. After 28 days of feeding, the WGR and SGR in the treatment group were significantly higher than those achieved in the control group $(p<0.05)$.

Table 2. Growth performance of crawfish fed with different experimental diets for 14 and 28 days.

\begin{tabular}{ccccc}
\hline \multirow{2}{*}{ Parameters } & \multicolumn{4}{c}{ Dietary Treatments } \\
\cline { 2 - 5 } & CG14d & TG14d & CG28d & TG28d \\
\hline Initial weight $(\mathrm{g})$ & $13.72 \pm 0.18$ & $13.69 \pm 0.21$ & $13.72 \pm 0.18$ & $13.69 \pm 0.21$ \\
Weight at sampling $(\mathrm{g})$ & $15.13 \pm 0.32$ & $15.45 \pm 0.39$ & $16.67 \pm 0.38 \mathrm{a}$ & $17.43 \pm 0.37 \mathrm{~b}$ \\
WGR (\%) & $10.13 \pm 0.43$ & $12.86 \pm 0.57$ & $21.61 \pm 1.03 \mathrm{a}$ & $27.09 \pm 1.87 \mathrm{~b}$ \\
SGR $(\% / \mathrm{d})$ & $0.69 \pm 0.04$ & $0.81 \pm 0.13$ & $0.72 \pm 0.05 \mathrm{a}$ & $0.86 \pm 0.07 \mathrm{~b}$ \\
Survival rate $(\%)$ & $95.83 \pm 1.44$ & $96.25 \pm 1.25$ & $92.08 \pm 0.72$ & $93.75 \pm 1.25$ \\
\hline
\end{tabular}

Note: CG14d and CG28d represents the control group after 14 days and 28 days of feeding. TG14d and TG28d represents the treatment group (S. cerevisiae at $10^{7} \mathrm{CFU} / \mathrm{g}$ diet) after 14 days and 28 days of feeding. Each value represents mean $\pm \operatorname{SD}(n=3)$, and bars with different letters indicate a significant different by LSD test for each time point $(p<0.05)$.

\subsection{Intestinal Morphology Changes}

After 14 days and 28 days of feeding, the crayfish intestines of treatment group exhibited an orderly and tight chitin layer, epithelial layer, connective tissue layer, muscle layer, and adventitia (Figure 1C,D). By contrast, the intestines of crayfish from the control group showed an oedema connective tissue layer and weak muscle layer (Figure 1A,B) 

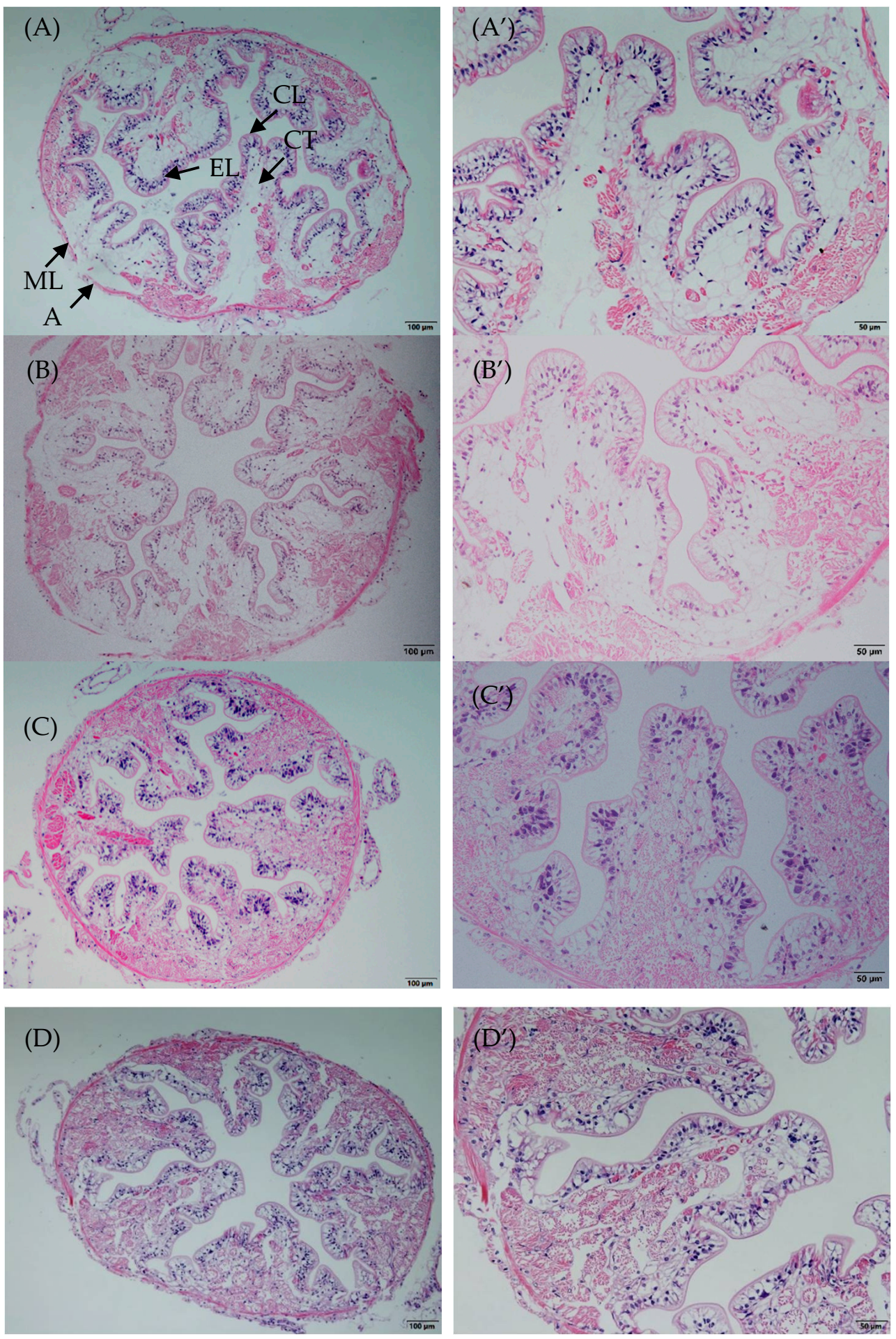

Figure 1. Intestinal morphology analysis of crayfish fed with different experimental diets for 14 days and 28 days. (A) control group after 14 days of feeding $\left((\mathbf{A}): 100 \times,\left(\mathbf{A}^{\prime}\right): 50 \times\right) ;(\mathbf{B})$ control group after 28 days of feeding $\left((\mathbf{B}): 100 \times,\left(\mathbf{B}^{\prime}\right): 50 \times\right) ;(\mathbf{C})$ treatment group (S. cerevisiae at $10^{7} \mathrm{CFU} / \mathrm{g}$ diet) after 14 days of feeding $\left((\mathbf{C}): 100 \times,\left(\mathbf{C}^{\prime}\right): 50 \times\right)$; (D) treatment group (S. cerevisiae at $10^{7} \mathrm{CFU} / \mathrm{g}$ diet) after 28 days of feeding $\left((\mathbf{D}): 100 \times,\left(\mathbf{D}^{\prime}\right): 50 \times\right)$. CL: chitinous layer; EL: epithelial layer; CT: connective tissue layer; ML: muscle layer; A: adventitia. 


\subsection{Expression Levels of Immunity-Related Genes in the Hepatopancreas}

The expression levels of immunity-related genes from the crayfish hepatopancreas tissue were detected after treatment with the two different diets, including the genes encoding Crustin2, lysozyme, prophenoloxidase, and the toll-like receptor (Figure 2). Compared with that in the control group, the relative expression of Crustin2 in the treatment group showed no significant difference. However, Lysozyme and prophenoloxidase gene expression levels were upregulated significantly $(p<0.05)$ after 14 days and 28 days of feeding. Prophenoloxidase showed the highest expression, with 10.5- and 8.2-fold higher expression in the treatment group than in the control group at 14 days and 28 days, respectively. There was no significant change in the expression of the toll-like receptor gene after 14 days of feeding. However, it was upregulated significantly $(p<0.05)$ after 28 days of feeding.
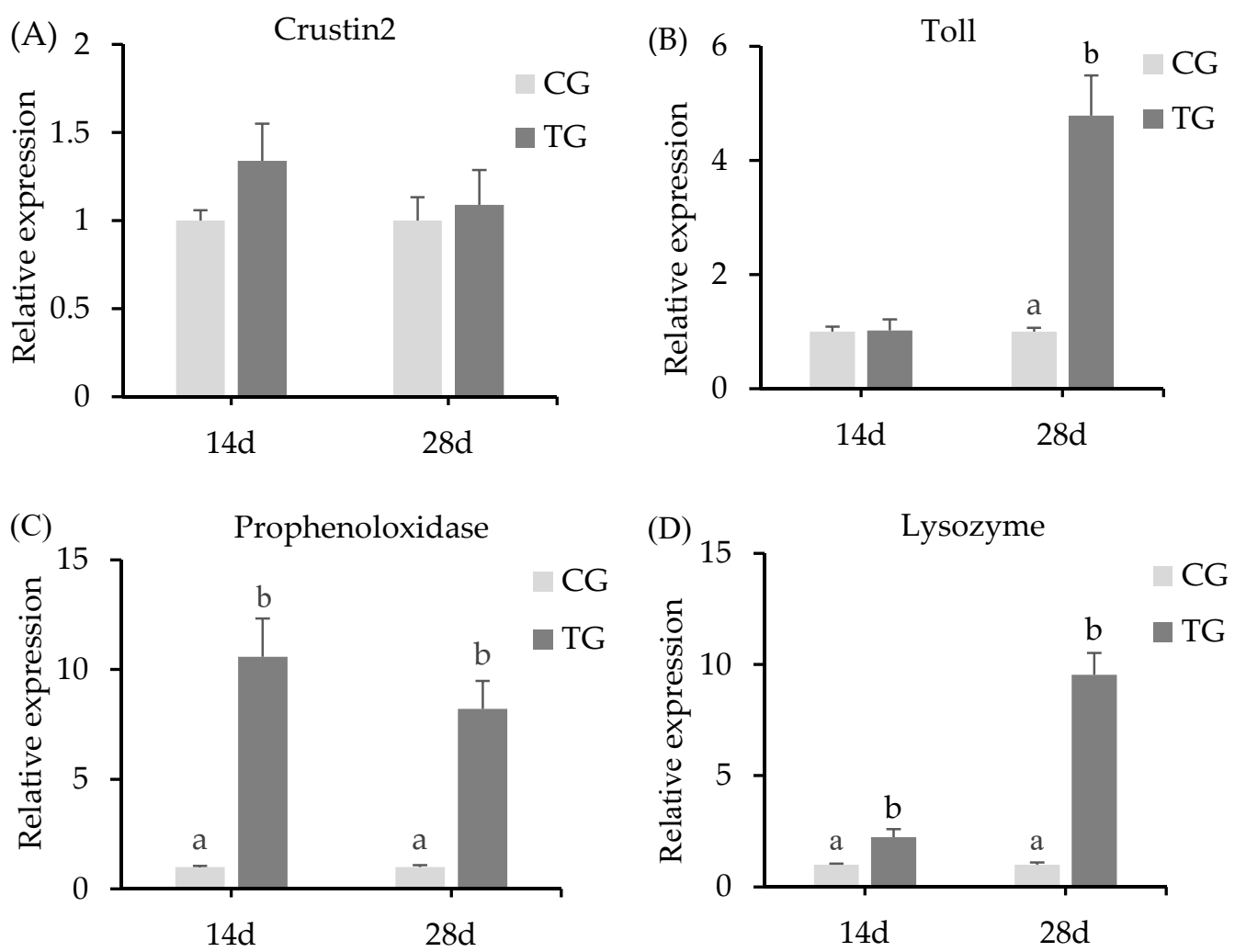

Figure 2. Relative mRNA expression of immunity-related genes in crayfish hepatopancreas tissue after the feeding trial. (A): Crustin2 gene expression; (B): toll gene expression; (C): prophenoloxidase gene expression; (D): lysozyme gene expression. Each value represents mean $\pm \mathrm{SD}(n=3)$, and bars with different letters indicate significant differences by the LSD test for each time point $(p<0.05)$. CG, control group; TG, treatment group (S. cerevisiae at $10^{7} \mathrm{CFU} / \mathrm{g}$ diet).

\subsection{Richness and Diversity of Intestinal Microbiota}

The 16S rRNA gene amplicons of microbiota were sequenced for the intestines of experimental crayfish. NGS raw data were deposited on NCBI (ID number: RJNA740135). The average number of OTUs obtained from the different samples ranged from 171 to 241, and the coverage rate of OTUs was above $99.9 \%$ (Table 3). The results showed that the Chao 1 indexes of TG14d and TG28d were significantly higher than those of CG14d and CG28d $(p<0.05)$. The OTUs and the Shannon index of TG14d were significantly higher than those of CG14d and CG28d ( $p<0.05)$. 
Table 3. OTUs classification information and alpha diversity index of microbial community in the intestines of crayfish.

\begin{tabular}{cccc}
\hline Sample ID & OTUs & Chao 1 & Shannon \\
\hline CG14d & $170 \pm 28 \mathrm{a}$ & $207.08 \pm 15.89 \mathrm{a}$ & $2.33 \pm 0.27 \mathrm{a}$ \\
TG14d & $241 \pm 31 \mathrm{~b}$ & $258.97 \pm 28.48 \mathrm{~b}$ & $2.97 \pm 0.32 \mathrm{~b}$ \\
CG28d & $171 \pm 17 \mathrm{a}$ & $201.04 \pm 9.75 \mathrm{a}$ & $2.42 \pm 0.15 \mathrm{a}$ \\
TG28d & $228 \pm 23 \mathrm{ab}$ & $250.16 \pm 16.48 \mathrm{~b}$ & $2.85 \pm 0.39 \mathrm{ab}$ \\
\hline
\end{tabular}

Note: each value represents mean \pm SD $(n=3)$. Different letters are significantly $(p<0.05)$ different by the LSD test. CG14d, control group after 14 days of feeding; CG28d, control group after 28 days of feeding; TG14d, treatment group (S. cerevisiae at $10^{7} \mathrm{CFU} / \mathrm{g}$ diet) after 14 days of feeding; TG28d, treatment group (S. cerevisiae at $10^{7} \mathrm{CFU} / \mathrm{g}$ diet) after 28 days of feeding; OUT, operational taxonomic unit.

\subsection{Phylum and Genus Performance}

To further explore the composition of the microbiota community richness in each group, the abundance of the intestinal microbiota was calculated in each group at the phylum and genus levels for the top ten bacteria. At the phylum level, Bacteroidetes, Firmicutes, Fusobacteria, and Proteobacteria were the primary intestinal microbiota in all groups (Figure 3). Compared with that of the control group, the relative abundance of Firmicutes increased after 14 days and 28 days of feeding, whereas the relative abundance of Bacteroidetes and Proteobacteria decreased in the treatment group. At the genus level, the primary intestinal microbiota in all groups were Bacteroides, Cetobacterium, Citrobacter, and Lactobacillus (Figure 3). The relative abundance of Cetobacterium and Lactobacillus increased in the treatment group, whereas Bacteroides and Citrobacter decreased, after 14 days and 28 days of feeding compared with that in the control group.

(A)

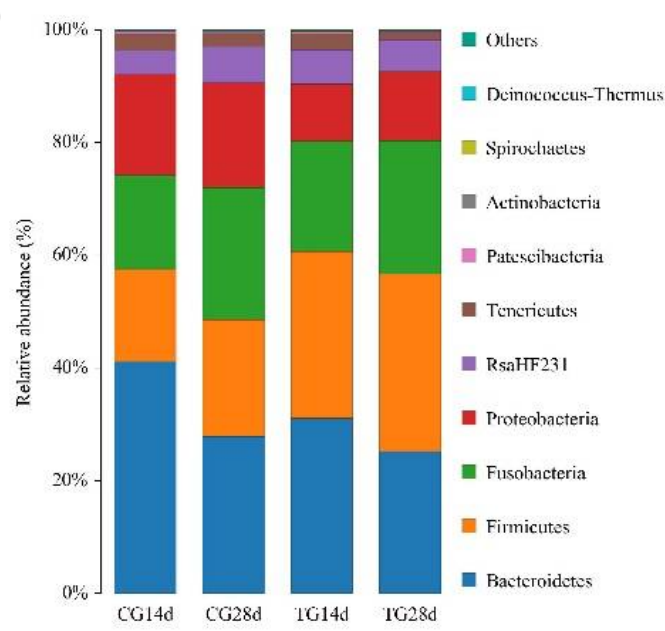

phylum level
$(\mathrm{B})_{100 \%}$

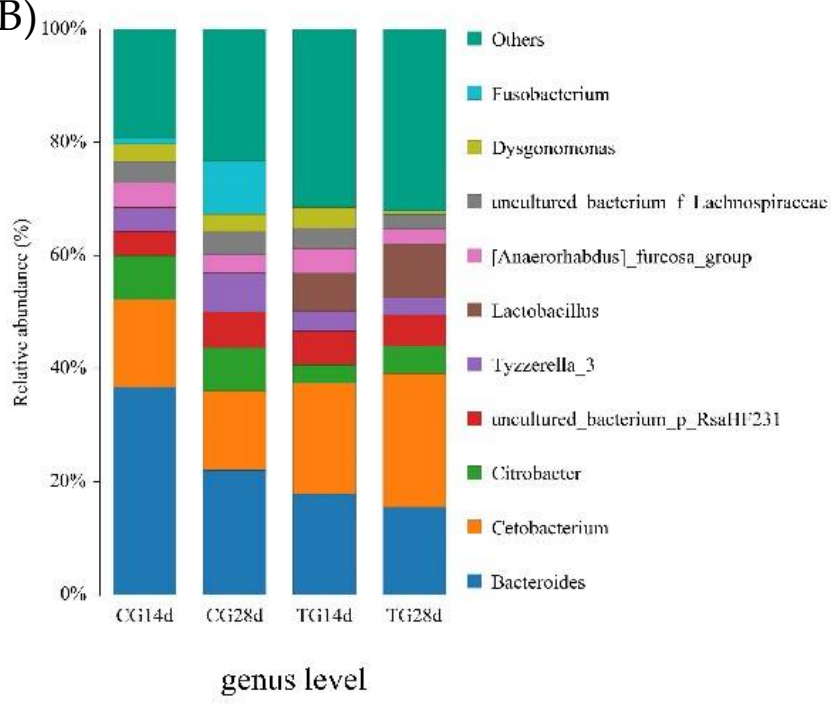

Figure 3. Relative abundance of the intestinal microbiota of crayfish at the phylum (A) and genus (B) levels. CG14d, control group after 14 days of feeding; CG28d, control group after 28 days of feeding; TG14d, treatment group (S. cerevisiae at $10^{7} \mathrm{CFU} / \mathrm{g}$ diet) after 14 days of feeding; TG28d, treatment group (S. cerevisiae at $10^{7} \mathrm{CFU} / \mathrm{g}$ diet) after 28 days of feeding.

\subsection{Principle Coordinate Analysis ( $P C O A)$}

The relationships between the microbiota communities from the different groups were evaluated using principal coordinate analysis with the unweighted UniFrac method. After 14 days and 28 days of feeding, the community structure of the intestinal microbiota from the treatment group was distant to that of the control group (Figure 4). In addition, compared with that of the control group, the intestinal microbial community structure of the treatment group was clustered closer after 14 days and 28 days of feeding. 


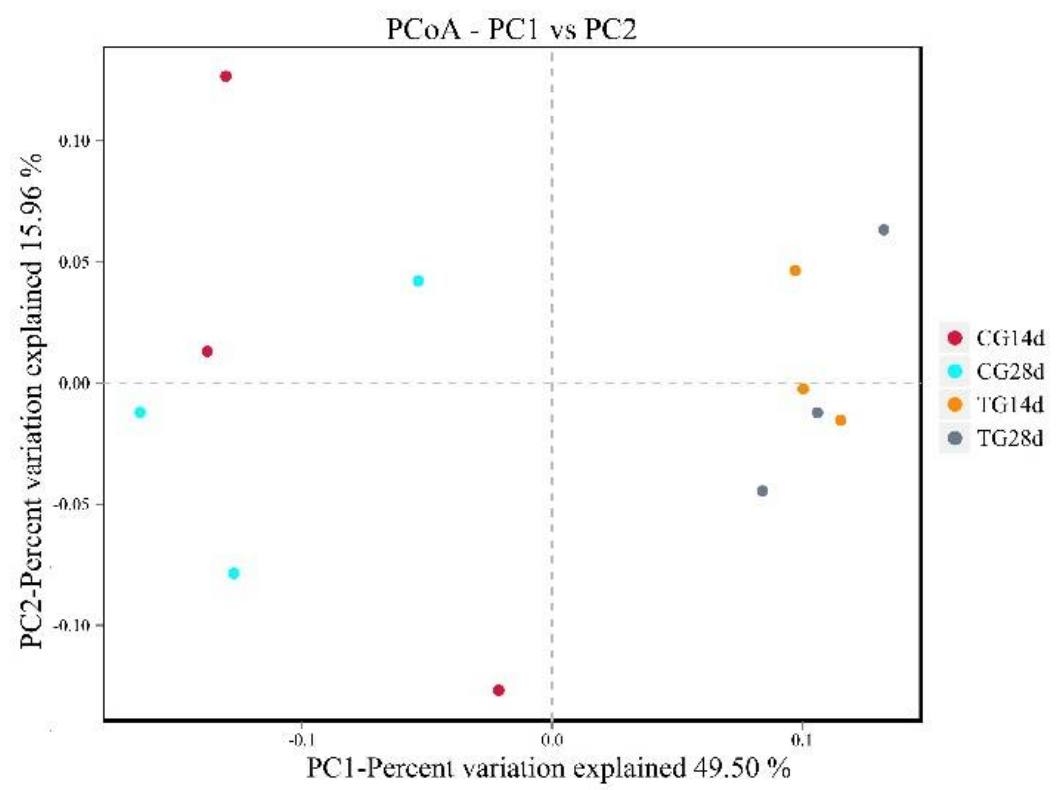

Figure 4. Principal coordinate analysis (PCoA) based on unweighted Unifrac distances. CG14d, control group after 14 days of feeding; CG28d, control group after 28 days of feeding; TG14d, treatment group (S. cerevisiae at $10^{7} \mathrm{CFU} / \mathrm{g}$ diet) after 14 days of feeding; TG28d, treatment group (S. cerevisiae at $10^{7} \mathrm{CFU} / \mathrm{g}$ diet) after 28 days of feeding.

\subsection{Challenge Test}

The cumulative survival rates of crayfish challenged with $C$. freundii for 10-days are shown in Figure 5. During the challenge test, the first mortalities occurred on the second day. At the end of the 10-day challenge test, the cumulative survival rates were $31.11 \%$, $37.78 \%, 60 \%$, and $65.56 \%$ in the CG14d, CG28d, TG14d, and TG28d groups, respectively. Crayfish from the treatment group showed a numerically higher survival rate compared with that in the control group after 14 days and 28 days of feeding.

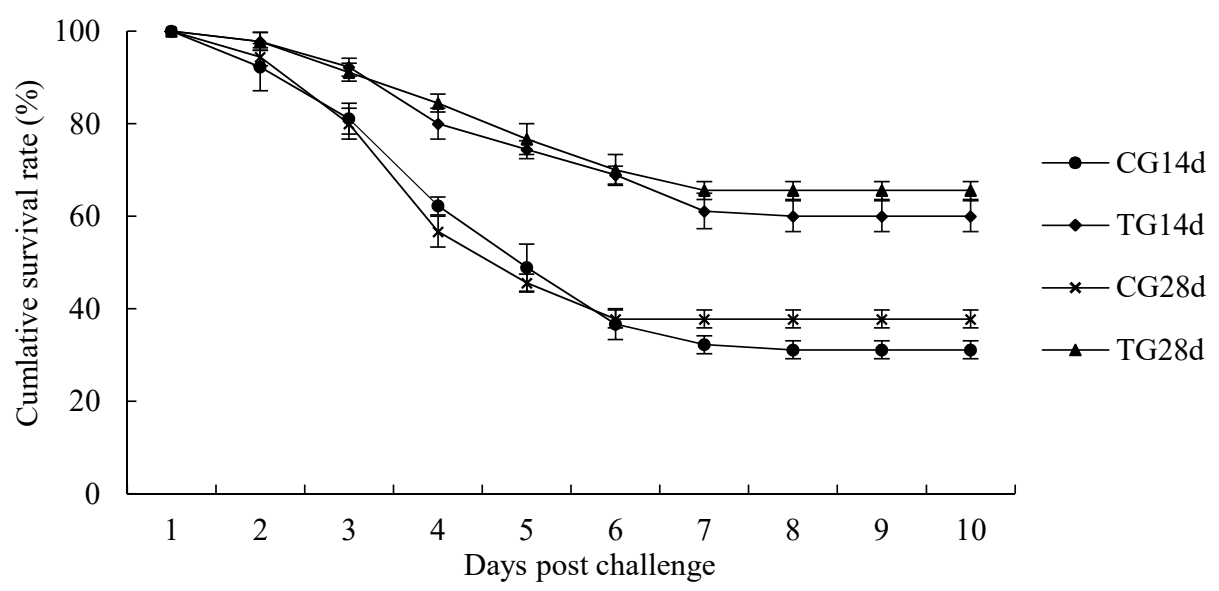

Figure 5. Cumulative survival following a 10-day $C$. freundii challenge in crayfish. Each value represents the mean $\pm \mathrm{SD}(n=3)$. Different letters were significantly $(p<0.05)$ different by LSD test. CG14d, control group after 14 days of feeding; CG28d, control group after 28 days of feeding; TG14d, treatment group (S. cerevisiae at $10^{7} \mathrm{CFU} / \mathrm{g}$ diet) after 14 days of feeding; TG28d, treatment group (S. cerevisiae at $10^{7} \mathrm{CFU} / \mathrm{g}$ diet) after 28 days of feeding. 


\section{Discussion}

\subsection{Growth Performance}

Dietary supplementation of probiotics in aquaculture offers an ecofriendly prophylactic measure to improve fish growth performance and health [30]. Probiotics might affect the host beneficially by improving immunity and the intestinal microbial balance [31] S. cerevisiae is an important source of products with probiotic activity [32]. It is rich in nutrients such as protein, functional polysaccharides, amino acids (glutamic acid), and vitamins (Vitamin B) [18]. In particular, the $\beta$-glucan and mannose oligosaccharides (MOS) in the yeast cell wall could improve the growth performance of giant freshwater prawn (Macrobrachium rosenbergii) [33], red sea bream (Pagrus major) [34], Chinese mitten crab (Eriocheir sinensis) [35], and other aquatic animals [36,37]. In the present study, S. cerevisiae at $10^{7} \mathrm{CFU} / \mathrm{g}$ in feed showed a growth-promoting effect on crayfish after $28 \mathrm{~d}$, which was similar to the above results.

\subsection{Intestinal Histomorphometric}

In aquatic animals, the intestine is the main organ for digestion and absorption [37]. The normal intestinal epithelial structure also plays an important role in the intestinal barrier function and the mucosal immune response $[38,39]$. S. cerevisiae feed additives have a positive effect on the intestine; for example, they promoted villi and epithelial cells growth and development in carp, Atlantic salmon (Salmo salar L), and white shrimp [17,40,41]. In the present study, the intestine exhibited an orderly and tight epithelial layer, connective tissue layer, and muscle layer without edema after the crayfish were fed with S. cerevisiae. This might be because it increased the nucleotide contents of intestinal cells, which promoted DNA and RNA synthesis in the intestinal mucosa and improved bowel morphology [42].

\subsection{Immune Related Gene Expressions}

Crayfish lack typical adaptive immunity and instead rely on their innate immune systems to combat pathogenic invasion [9]. Changes in the expression levels of immunerelated genes are important indicators of the health state of crayfish, and the intestinal microbiota balance can promote the improvement of immunity [43]. In this work, toll-like receptors, prophenoloxidase, Crustin2, and lysozyme genes in hepatopancreases of crayfish were determined. Toll-like receptors and prophenoloxidase can transmit invasion signals and induce a series of downstream cascade reactions [10]. Crustin2 and lysozyme have important antibacterial and antiviral effects $[11,12]$. S. cerevisiae could enhance the activities of prophenoloxidase and toll-receptor expression in the hepatopancreas of giant freshwater prawn [44]. In addition, the marine yeast Yarrowia lipolytica could upregulate the expression of prophenoloxidase and lysozyme in white shrimp [45]. In this study, the crayfish fed with S. cerevisiae showed significantly increased expression of Lysozyme, prophenoloxidase, and toll-like receptor genes in the hepatopancreas. This might reflect the abundant $\beta-1$, 3 -glucan in the cell wall of $S$. cerevisiae, which could promote the expression of immune genes in aquatic animals $[46,47]$. However, there was no significant effect on Crustin2 gene expression in the crayfish hepatopancreas of the S. cerevisiae-fed group. This might be related to different factors, such as the pathway of immune gene expression and the mechanism of Crustin2's participation in immune regulation [48].

\subsection{Intestinal Microbiota Analysis}

Normally, the beneficial and harmful bacteria in the intestinal tract are in a dynamic balance [16]. This balance maintains the stability of the intestinal environment, which can help the body to inhibit the invasion of foreign pathogenic bacteria effectively and enhance the body's non-specific immunity [49]. The dynamic balance of the intestinal microbiota of aquatic animals is affected by many factors, such as their own physiological state, feed composition, external stress, and water environment [50-52]. In this study, the distribution in PCoA suggested that the microbiota community structure in the intestines of crayfish after feeding with S. cerevisiae was more stable than that of the control group. From the 
perspective of phylum classification, the dominant phyla of both groups were Firmicutes, Bacteroidetes, Fusobacteria, and Proteobacteria in the intestines of crayfish. Compared with that in the control group, the abundance of Firmicutes increased, but that of Bacteroidetes and Proteobacteria decreased after feeding S. cerevisiae for 14 days and 28 days. As symbiotic bacteria in the intestines of crustacea, the prevalence of Proteobacteria, including harmful pathogens such as Escherichia coli and Vibrio cholerae, has been proposed as the potential signature of dysbiosis and risk of disease [53]. Firmicutes are defined as beneficial bacteria of the intestines, and their positive role in growth performance, immunity, digestion, and disease resistance of aquatic animals has been noted [54,55]. S. cerevisiae might improve intestinal health by increasing the proliferation of Firmicutes and inhibiting the growth of Proteobacteria [56].

At the genus level, the common bacteria in the intestines of crayfish are Bacteroides, Cetobacterium, and Citrobacter [3]. In the present study, Bacteroides, Cetobacterium, Citrobacter, and Lactobacillus were the dominant genera in the intestines of crayfish from both groups. Cetobacterium has been observed in high relative abundance in different freshwater fishes and could produce large quantities of vitamin B-12 [57]. Lactobacillus can reduce the intestinal $\mathrm{pH}$, which might contribute to overcoming pathogen challenges [22]. Bacteroides could result in damage to intestinal tissues [58]. Citrobacter is an opportunistic bacterium in crayfish culture [6]. Although not statistically different, our results show that the relative abundances of Cetobacterium and Lactobacillus in the crayfish intestines from treatment group increased, and those of Citrobacter and Bacteroides decreased after feeding with S. cerevisiae for 14 days and 28 days. This might have been because the $S$. cerevisiae cell wall is rich in mannose oligosaccharides and $\beta$-glucans, which can promote the proliferation of probiotics [47]. In addition, the acidic substances produced after mannose oligosaccharide production are selectively fermented by intestinal microbiota, which will lower the $\mathrm{pH}$ value of the intestine and inhibit the growth of harmful bacteria [30].

\subsection{Disease Resistance Analysis}

C. freundii can invade shrimp and produce independent factors leading to disease outbreaks. [6]. A challenge test showed that $C$. freundii exhibited significant virulence to crayfish, with an LD50 value of $1.71 \times 10^{6} \mathrm{CFU} / \mathrm{mL}$ [6]. In this study, after a 10-day challenge with a higher concentration $\left(2.5 \times 10^{7} \mathrm{CFU} / \mathrm{mL}\right)$ of $C$. freundii, the cumulative survival rate was $30-40 \%$ in the control group. Meanwhile, dietary supplementation of S. cerevisiae increased the survival rate in the challenge test to above $60 \%$. It might be due to the increased abundance of intestinal probiotics and up-regulation of immune genes with defense and antimicrobial functions after feeding after S. cerevisiae feeding, thereby enhancing resistance to pathogens invasion and infection [59].

\section{Conclusions}

In this study, the addition of S. cerevisiae YFI-SC2 in diet at $10^{7} \mathrm{CFU} / \mathrm{g}$ positively influenced the growth performance, the immune response, the intestinal microbiota structure, and the resistance to pathogens in crayfish. As long-term fresh S. cerevisiae YFI-SC2 are fed in the diet, a more pronounced effect will be observed. Therefore, S. cerevisiae YFI-SC2 can be used as a potential probiotic in crayfish farming.

Author Contributions: Y.Z., Y.X. and Y.L. conceived and designed the study, performed the data collection, analysis, statistical analysis, the writing of the manuscript, software, and the literature review. Y.X., X.L. and G.L. conducted animal management and sample collections. Y.M., W.L. and M.X. performed the microbial analysis, immunity analysis, and literature review. Y.Z., Y.F., T.Y., B.L. and L.Z. reviewed and edited the manuscript. All authors have read and agreed to the published version of the manuscript.

Funding: This work was supported by the National Key Research Development Program of China (No. 2019YFD0900105), the Central Public-Interest Scientific Institution Basal Research Fund (No. 2020TD44), and the Central Public-Interest Scientific Institution Basal Research Fund, CAFS (NO.2019ZY17). 
Institutional Review Board Statement: All experimental procedures were conducted according to guidelines of the appropriate Animal Experimental Ethical Inspection of Laboratory Animal Centre, Yangtze River Fisheries Research Institute, Chinese Academy of Fishery Sciences (ID Number: YFI2021-zhouyong-01).

Data Availability Statement: The data presented in this study are available on request from the corresponding author.

Acknowledgments: We would like to thank Guangdong Yuequn and the Ocean Biological Research Development Co., Ltd. for their support in carrying out this study.

Conflicts of Interest: The authors declare no conflict of interest.

\section{References}

1. Harris, D.J.; Crandall, K.A. Intragenomic variation within ITS1 and ITS2 of freshwater crayfishes (Decapoda: Cambaridae): Implications for phylogenetic and microsatellite studies. Mol. Biol. Evol. 2000, 17, 284-291. [CrossRef]

2. Xiong, B.; Xu, T.; Li, R.P.; Johnson, D.; Ren, D.; Liu, H.G.; Xi, Y.; Huang, Y.P. Heavy metal accumulation and health risk assessment of crayfish collected from cultivated and uncultivated ponds in the Middle Reach of Yangtze River. Sci. Total Environ. 2020, 739, 139963. [CrossRef]

3. Liu, Q.; Long, Y.N.; Li, B.; Zhao, L.L.; Luo, X.; Xu, L.; Luo, W.; Du, Z.J.; Zhou, J.; Yang, S. Rice-shrimp culture: A better intestinal microbiota, immune enzymatic activities, and muscle relish of crayfish (Procambarus clarkii) in Sichuan Province. Appl. Microbiol. Biot. 2020, 104, 9413-9420. [CrossRef]

4. The State of World Fisheries and Aquaculture; Sustainability in Action, Food and Agriculture Organization of the United Nations: Rome, Italy, 2020; Volume 30.

5. Fisheries and Fisheries Administration Bureau of Ministry of Agriculture and Industry. China Fisheries Yearbook; China Agriculture Press: Beijing, Chinese, 2020; Volume 26.

6. Liu, X.D.; He, X.; An, Z.H.; Sun, W.; Chen, N.; Gao, X.J.; Li, X.X.; Zhang, X.J. Citrobacter freundii infection in red swamp crayfish (Procambarus clarkii) and host immune-related gene expression profiles. Aquaculture 2020, 515, 734499. [CrossRef]

7. Zhang, Y.; Li, Z.Y.; Sergey, K.; Andrey, S.; Chen, C.; Feng, Y.J.; Ren, N.Q.; Sun, K. Effects of cadmium on intestinal histology and microbiota in freshwater crayfish (Procambarus clarkii). Chemosphere 2020, 242, 125105. [CrossRef] [PubMed]

8. Joseph, E.B.; Karen, G.B.; Louis, E.B. Disease resistance of Pacific white shrimp, Litopenaeus vannamei, following the dietary administration of a yeast culture food supplement. Aquaculture 2003, 231, 1-8.

9. Sruthy, K.S.; Nair, A.; Puthumana, J.; Antony, S.P.; Singh, I.B.; Philip, R. Molecular cloning, recombinant expression and functional characterization of an antimicrobial peptide, Crustin from the Indian white shrimp, Fenneropenaeus indicus. Fish Shellfish Immunol. 2017, 71, 83-94. [CrossRef] [PubMed]

10. Lee, S.Y.; Kenneth, S. Early events in crustacean innate immunity. Fish Shellfish Immunol. 2002, 12, 421-443.

11. Li, F.H.; Xiang, J.H. Recent advances in researches on the innate immunity of shrimp in China. Dev. Comp. Immunol. 2013, 39, 11-26. [CrossRef]

12. Liu, H.T.; Wang, J.; Mao, Y.; Liu, M.; Niu, S.F.; Qiao, Y.; Su, Y.Q.; Wang, C.Z.; Zheng, Z.P. Identification and expression analysis of a new invertebrate lysozyme in Kuruma shrimp (Marsupenaeus japonicus). Fish Shellfish Immunol. 2016, 49, 336-343. [CrossRef]

13. Peera, H.; James, V. Effects of probiotics on gut microbiota: Mechanisms of intestinal immunomodulation and neuromodulation. Ther. Adv. Gastroenter. 2013, 6, 39-51.

14. Seyed, H.H.; Einar, R.; Alireza, S.M.; Maria, Á.E. Probiotic, prebiotic and synbiotic supplements in sturgeon aquaculture: A review. Rev. Aquacult. 2016, 8, 89-102.

15. Ortuño, J.; Cuesta, A.; Rodriguez, A.; Esteban, M.; Meseguer, J. Oral administration of yeast, Saccharomyces cerevisiae enhances the cellular innate immune response of gilthead seabream (Sparus aurata L.). Vet. Immunol. Immunopathol. 2002, 85, 41-50. [CrossRef]

16. Wang, S.J.; Guo, C.H.; Zhou, L.; Zhong, Z.D.; Zhu, W.Z.; Huang, Y.L.; Zhang, Z.F.; Gorgels, T.G.; Berendschot, T.T. Effects of dietary supplementation with epidermal growth factor expressing Saccharomyces cerevisiae on duodenal development in weaned piglets. Brit. J. Nutr. 2016, 115, 1509-1520. [CrossRef]

17. Zhang, P.Y.; Yang, F.; Hu, J.P.; Han, D.; Liu, H.K.; Jin, J.Y.; Yang, Y.X.; Yi, J.H.; Zhu, X.M.; Xie, S.Q. Optimal form of yeast cell wall promotes growth, immunity and disease resistance in gibel carp (Carassius auratus gibelio). Aquac. Rep. 2020, 18, 100465. [CrossRef]

18. Huang, L.; Ran, C.; He, S.X.; Ren, P.F.; Hu, J.; Zhao, Z.X.; Zhou, Z.J. Effects of dietary Saccharomyces cerevisiae culture or live cells with Bacillus amyloliquefaciens spores on growth performance, gut mucosal morphology, hsp70 gene expression, and disease resistance of juvenile common carp (Cyprinus carpio). Aquaculture 2015, 438, 33-38. [CrossRef]

19. Dias, M.K.R.; Yoshioka, E.T.O.; Rodriguez, A.F.R.; Ribeiro, R.A.; Faria, F.S.E.D.V.; Ozório, R.O.A.; Tavares-Dias, M. Growth and hematological and immunological responses of Arapaima gigas fed diets supplemented with immunostimulant based on Saccharomyces cerevisiae and subjected to handling stress. Aquac. Rep. 2020, 17, 100335. [CrossRef] 
20. Mohammad, A.; Shapour, K.; Mehrdad, M. Immunity enhancement with administration of Gracilaria corticata and Saccharomyces cerevisiae compared to gamma irradiation in expose to WSSV in shrimp, in juvenile Litopenaeus vannamei: A comparative study. Fish Shellfish Immunol. 2016, 56, 21-33.

21. Zhang, M.Z.; Pan, L.Q.; Fan, D.P.; He, J.J.; Su, C.; Gao, S.; Zhang, M.Y. Study of fermented feed by mixed strains and their effects on the survival, growth, digestive enzyme activity and intestinal flora of Penaeus vannamei. Aquaculture 2021, 530, 735703. [CrossRef]

22. Fang, H.; Wang, B.J.; Jiang, K.Y.; Liu, M.; Wang, L. Effects of Lactobacillus pentosus HC-2 on the growth performance, intestinal morphology, immune-related genes and intestinal microbiota of Penaeus vannamei affected by aflatoxin B1. Aquaculture 2020, 525, 735289. [CrossRef]

23. Shi, X.Z.; Zhang, R.R.; Jia, Y.P.; Zhao, X.F.; Yu, X.Q.; Wang, J.X. Identification and molecular characterization of a Spätzle-like protein from Chinese shrimp (Fenneropenaeus chinensis). Fish Shellfish Immunol. 2009, 27, 610-617. [CrossRef]

24. Li, Y.H.; Zheng, L.; Chen, H.Q.; Wang, H.Z.; Wang, L.Q.; Xu, D.P. Cloning and Sequence Analysis of Prophenoloxidase from Haemocytes of the Red Swamp Crayfish, Procambarus clarkii. Agric. Sci. China 2008, 8, 369-379. [CrossRef]

25. Wang, Z.; Chen, Y.H.; Dai, Y.J.; Tan, J.M.; Huang, Y.; Lan, J.F.; Ren, Q. A novel vertebrates Toll-like receptor counterpart regulating the anti-microbial peptides expression in the freshwater crayfish, Procambarus clarkii. Fish Shellish Immunol. 2015, 43, 219-229. [CrossRef]

26. Liu, B.; Zhou, Q.L.; Sun, C.X.; Song, C.Y.; Zhang, H.M.; Yang, Z.F.; Shan, F. Patterns of Bacterial Community Composition and Diversity Following the Embryonic Development Stages of Macrobrachium rosenbergii. Aquac. Rep. 2020, 17, 100372. [CrossRef]

27. Schloss, P.D.; Westcott, S.L.; Ryabin, T.; Hall, J.R.; Hartmann, M.; Hollister, E.B.; Lesniewski, R.A.; Oakley, B.B.; Parks, D.H.; Robinson, C.J.; et al. Introducing mothur: Open-source, platform-independent, community-supported software for describing and comparing microbial communities. Appl. Environ. Microbiol. 2009, 75, 7537-7541. [CrossRef]

28. Wang, Q.; Garrity, G.M.; Tiedje, J.M.; Cole, J.R. Naive Bayesian classifier for rapid assignment of rRNA sequences into the new bacterial taxonomy. Appl. Environ. Microbiol. 2007, 73, 5261-5267. [CrossRef]

29. Grice, A.; Kong, H.H.; Conlan, S.; Deming, C.B.; Davis, J.; Young, A.C.; Bouffard, G.G.; Blakesley, R.W.; Murray, P.R.; Green, E.D.; et al. Topographical and temporal diversity of the human skin microbiome. Science 2009, 324, 1190-1192. [CrossRef] [PubMed]

30. Das, A.; Nakhro, K.; Chowdhury, S.; Kamilya, D. Effects of potential probiotic Bacillus amyloliquefaciens FPTB16 on systemic and cutaneous mucosal immune responses and disease resistance of catla (Catla catla). Fish Shellfish Immunol. 2013, 35, 1547-1553. [CrossRef]

31. Merrifield, D.; Bradley, G.; Baker, R.; Davies, S. Probiotic applications for rainbow trout (Oncorhynchus mykiss Walbaum) I. Effects on growth performance, feed utilization, intestinal microbiota and related health criteria. Aquac. Nutr. 2010, 16, 496-503. [CrossRef]

32. Caridad, S.; Guevara, C.A. Probiotic Use of Yeast Saccharomyces Cerevisiae in Animal Feed. Res. J. Zool. 2018, 1. [CrossRef]

33. Gupta, A.; Dhawan, A. Effect of dietary probiotic improval (Lactobacillus sporogenes and Saccharomyces cerevisiae) on growth and feed utilization of Macrobrachium rosenbergii post larvae. Anim. Nutr. Feed Technol. 2012, 12, $209-217$.

34. Dawood, M.A.O.; Koshio, S.; Ishikawa, M.; Yokoyama, S.; El Basuini, M.F.; Hossain, M.S.; Nhu, T.H.; Moss, A.S.; Dossou, S.; Wei, H. Dietary supplementation of $\beta$-glucan improves growth performance, the innate immune response and stress resistance of red sea bream, Pagrus major. Aquac. Nutr. 2017, 23, 148-159. [CrossRef]

35. Lu, J.T.; Qi, C.G.; Samwel, M.L.; Han, F.L.; Yang, L.; Wang, X.D.; Jian, G.Q.; Chen, L.Q. Dietary mannan oligosaccharide (MOS) improves growth performance, antioxidant capacity, non-specific immunity and intestinal histology of juvenile Chinese mitten crabs (Eriocheir sinensis). Aquaculture 2019, 510, 337-346. [CrossRef]

36. Waraporn, H.; Karun, T.; Naraid, S. Effects of dietary supplementation of oligosaccharides on growth performance, gut health and immune response of hybrid catfish (Pangasianodon gigas $\times$ Pangasianodon hypophthalmus). Aquaculture 2019, 507, 97-107.

37. Lee, S.; Katya, K.; Park, Y.; Won, S.; Seong, M.; Hamidoghli, A.; Bai, S.C. Comparative evaluation of dietary probiotics Bacillus subtilis WB60 and Lactobacillus plantarum KCTC3928 on the growth performance, immunological parameters, gut morphology and disease resistance in Japanese eel, Anguilla japonica. Fish Shellfish Immunol. 2017, 61, 201-210. [CrossRef]

38. Salah, M.A.; Yousef, A.A.; Ahlam, A.G.; Moahmed, F.M. Studies on Bacillus subtilis and Lactobacillus acidophilus, as potential probiotics, on the immune response and resistance of Tilapia nilotica (Oreochromis niloticus) to challenge infections. Fish Shellfish Immunol. 2008, 25, 128-136.

39. Magalhaes, J.G.; Tattoli, I.; Girardin, S.E. The intestinal epithelial barrier: How to distinguish between the microbial flora and pathogens. Semin. Immunol. 2007, 19, 106-115. [CrossRef]

40. Burrells, C.; Williams, P.D.; Southgate, P.J. Dietary nucleotides: A novel supplement in fish feeds: 2. Effectson vaccination, salt water transfer, growth rates and physiology of Atlantic salmon (Salmo salar L). Aquaculture 2001, 199, 171-184. [CrossRef]

41. Yao, W.X.; Li, X.Q.; Zhang, C.Y.; Wang, J.; Cai, Y.W.; Leng, X.J. Effects of dietary synbiotics supplementation methods on growth, intestinal health, non-specific immunity and disease resistance of Pacific white shrimp, Litopenaeus vannamei. Fish Shellfish Immunol. 2021, 112, 46-55. [CrossRef]

42. Rebeca, C.; Milena, F.; Silvana, T.T.; José, M.; Miguel, Á.M.; Ángeles, E. Histological alterations and microbial ecology of the intestine in gilthead seabream (Sparus aurata L.) fed dietary probiotics and microalgae. Cell Tissue Res. 2012, 350, 477-489. 
43. Yang, X.Y.; He, Y.F.; Chi, S.Y.; Tan, B.P.; Lin, S.; Dong, X.H.; Yang, Q.H.; Liu, H.Y.; Zhang, S. Supplementation with Saccharomyces cerevisiae hydrolysate in a complex plant protein, low-fishmeal diet improves intestinal morphology, immune function and Vibrio harveyi disease resistance in Epinephelus coioides. Aquaculture 2020, 529, 735655. [CrossRef]

44. Miao, S.Y.; Han, B.; Zhao, C.Z.; Hu, J.T.; Zhu, J.Y.; Zhang, X.; Sun, L.S. Effects of dietary Pediococcus acidilactici GY2 single or combined with Saccharomyces cerevisiae or/and $\beta$-glucan on the growth, innate immunity response and disease resistance of Macrobrachium rosenbergii. Fish Shellfish Immunol. 2020, 98, 68-76. [CrossRef]

45. Alan, L.J.; Ángel, C.C.; Antonio, L.G.; Ilie, S.R.; Marlene, T.; Carlos, A. Dietary supplementation of marine yeast Yarrowia lipolytica modulates immune response in Litopenaeus vannamei. Fish Shellfish Immunol. 2020, 105, 469-476.

46. Zhao, Y.C.; Ma, H.M.; Zhang, W.B.; Qing, H.; Ai, K.S.; Mai, W.; Xu, X.J.; Wang, Z.G.; Liu, F. Effects of dietary $\beta$-glucan on the growth, immune responses and resistance of sea cucumber, Apostichopus japonicus against Vibrio splendidus infection. Aquaculture 2011, 315, 269-274. [CrossRef]

47. Biswas, G.; Korenaga, H.; Takayama, H.; Kono, T.; Shimokawa, H.; Sakai, M. Cytokine responses in the common carp, Cyprinus carpio L. treated with baker's yeast extract. Aquaculture 2012, 356-357, 169-175. [CrossRef]

48. Liang, Q.J.; Li, Z.H.; Ou, M.F.; Wu, X.J.; Qiao, X.L.; Wei, W.; Liu, Y.; Ye, J.M.; Wang, W.N. Hypoimmunity and intestinal bacterial imbalance are closely associated with blue body syndrome in cultured Penaeus vannamei. Aquaculture 2020, 522, 735118. [CrossRef]

49. Zhang, M.L.; Sun, Y.H.; Liu, Y.H.; Qiao, F.; Chen, L.Q.; Liu, W.T.; Du, Z.Y.; Li, E. Response of gut microbiota to salinity change in two euryhaline aquatic animals with reverse salinity preference. Aquaculture 2016, 454, 72-80. [CrossRef]

50. Emilie, C.; Yannick, G.; Kevin, M.; Bénédicte, L.; David, P.; Fabien, P.; Florian, N.; Denis, S. Bacterial community characterization of water and intestine of the shrimp Litopenaeus stylirostris in a biofloc system. BMC Microbiol. 2016, 16, 157-165.

51. Oscar, C.; Thompson, C.; José, M.; Angel, G. Colonization and Impact of Disease and Other Factors on Intestinal Microbiota. Digest. Dis. Sci. 2007, 52, 2069-2077.

52. Daniel, L.M.; Dean, B.; Graham, B.; Simon, J.D.; Remi, T.M. Microbial community diversity associated with the intestinal mucosa of farmed rainbow trout (Oncoryhnchus mykiss Walbaum). Aquac. Res. 2009, 40, 1064-1072.

53. Shin, N.R.; Whon, T.W.; Bae, J.W. Proteobacteria: Microbial signature of dysbiosis in gut microbiota. Trends Biotechnol. 2015, 33, 496-503. [CrossRef]

54. Miao, S.Y.; Zhao, C.Z.; Zhu, J.Y.; Hu, J.T.; Dong, X.J.; Sun, L.S. Dietary soybean meal affects intestinal homoeostasis by altering the microbiota, morphology and inflammatory cytokine gene expression in northern snakehead. Sci. Rep. 2018, 8, 113-122. [CrossRef] [PubMed]

55. Dong, J.; Li, X.D.; Zhang, R.Y.; Zhao, Y.Y.; Wu, G.F.; Liu, J.L.; Zhu, X.C.; Li, L. Comparative analysis of the intestinal bacterial community and expression of gut immunity genes in the Chinese Mitten Crab (Eriocheir sinensis). AMB Express 2018, 8, 192. [CrossRef]

56. Wang, A.R.; Ran, C.; Einar, R.; Zhou, Z.G. Progress in fish gastrointestinal microbiota research. Rev. Aquacult. 2018, 10, 626-640. [CrossRef]

57. Tsuchiya, C.; Sakata, T.; Sugita, H. Novel ecological niche of Cetobacterium somerae, an anaerobic bacterium in the intestinal tracts of freshwater fish. Lett. Appl. Microbiol. 2008, 46, 43-48. [CrossRef]

58. Zhang, Y.; Zhang, P.J.; Shang, X.C.; Lu, Y.T.; Li, Y.H. Exposure of lead on intestinal structural integrity and the diversity of gut microbiota of common carp. Comp. Biochem. Physiol. Part C 2021, 239, 108877. [CrossRef]

59. Stephen, A.; Shen, J.F.; Tan, B.P.; Dong, X.H.; Liu, H.Y. Effects of dietary yeast culture on shrimp growth, immune response, intestinal health and disease resistance against Vibrio harveyi. Fish Shellfish Immunol. 2020, 102, 286-295. 